\title{
A New Posterior Semi-fixed Temporary Bite Raising Appliance
}

\author{
Dr Achint Chachada,' Dr Sneha Pedgaonkar²
}

'Professor \& Head, Dept of Orthodontics, Chattisgarh Dental College \& Research Institute, Chattisgarh, India ${ }^{2}$ PG Student, Department of Orthodontics, Swargiya Dadasaheb Kalmegh Smruti Dental College \& Hospital, Nagpur, India

Correspondence: Dr Achint Chachada; Email: achint.chachada@gmail.com

\section{ABSTRACT}

In clinical scenarios like anterior cross bite and Angle's Class II division 2 malocclusion, it is often required to raise the bite temporarily for an effective unobstructed tooth movement of maxillary/mandibular incisors. For relieving the occlusion, numerous removable acrylic plates with bite blocks, glass ionomer splints or fixed bite blocks are commonly used. But each of these are having certain disadvantages. This technique describes semi-fixed posterior acrylic bite blocks which are fixed using "T" shaped spring to the vertically oriented lingual sheaths welded on molar bands both buccally and lingually for added retention. This technique has been found to be reliable and convenient, especially since it allows easy insertion and removal by the orthodontist and avoids the loosening of the bite block before patient's next visit and keeps the bite open as desired.

Keywords: Bite-Block, Semi-Fixed, Temporary Bite Raise.

\section{INTRODUCTION}

Fixed Orthodontic treatment involves bonding of attachments on tooth for effecting tooth movement. Many a times, in cases of anterior cross bite or Class II Division 2, teeth from opposing arch are obstructing the bracket placement i.e. in centric occlusion teeth from opposing arch lie onto the area of bracket placement on antagonist tooth or teeth. In such situations, there is a need to raise the bite temporarily. This article presents a new method of temporary bite raising which is Semifixed and can be easily removed by orthodontists. Being a semi-fixed appliance there is no need to remove the cement which might cause damage to enamel during removal. Various appliances have been proposed in literature for Temporary bite raising like Bite Raising crowns, Fixed anterior Bite Plane and Glass lonomer Cement or Composite Blobs on Occlusal surfaces of posterior teeth. 1,2 But as they are fixed, they do not allow proper hygiene maintenance and also require time to remove the cement with which they are fixed. Also, while removing the cement there may be some amount of damage to the enamel surface. These side effects can be eliminated with semi-fixed posterior bite blocks. This technique has been found to be reliable and convenient, especially since it allows easy insertion and removal by the patient himself which will help him in maintaining proper oral hygiene. The disadvantages of fixed bite block can be eliminated with this appliance as it is semi-fixed. Moreover, the bite block can be given unilaterally without any chance of swallowing it, because it is supported by wire both buccaly and lingually with locking mechanism on buccal side.

\section{Appliance Design and Step-wise Fabrication}

1. Adequate length of 21 gauge stainless steel wire is taken and bended in $T$ shape with horizontal arm of ' $T$ ' perpendicular to Vertical arm which forms lingual wire component. (Figure 1)

2. Adequate length of 23 gauge stainless steel wire is taken and bended into a cross (+) shaped spring forming buccal wire component. (Figure 2). Figure 3 shows the wire components with labelled parts.

3. Mandibular molar bands are fitted with vertically oriented lingual sheaths and buccal and lingual wire components are engaged in their respective slots.

4. Wire components are acrylized to form bite blocks and inserted in oral cavity. 


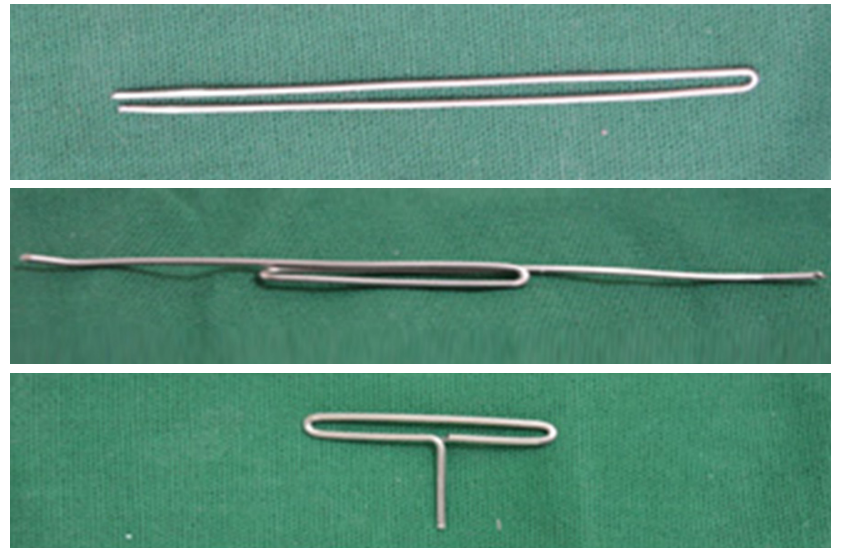

Figure 1: Steps in Fabrication of Lingual Wire Part

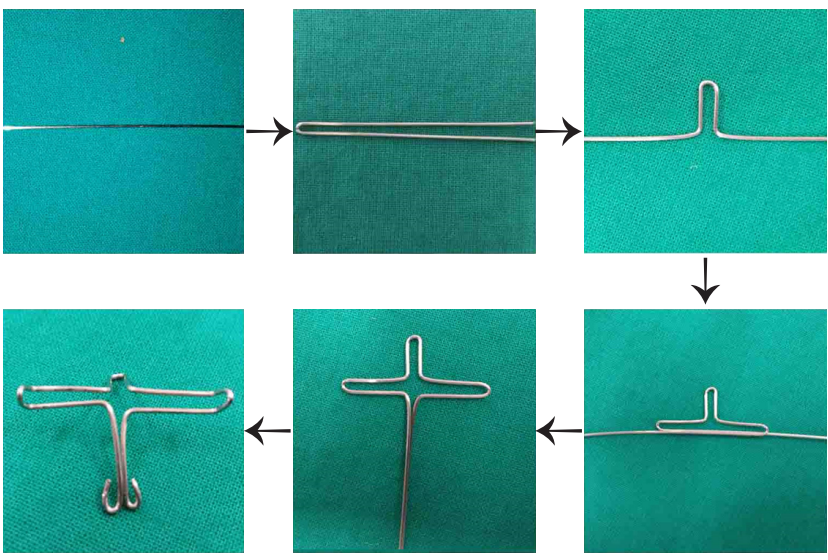

Figure 2: Steps in Fabrication of Buccal Wire Part

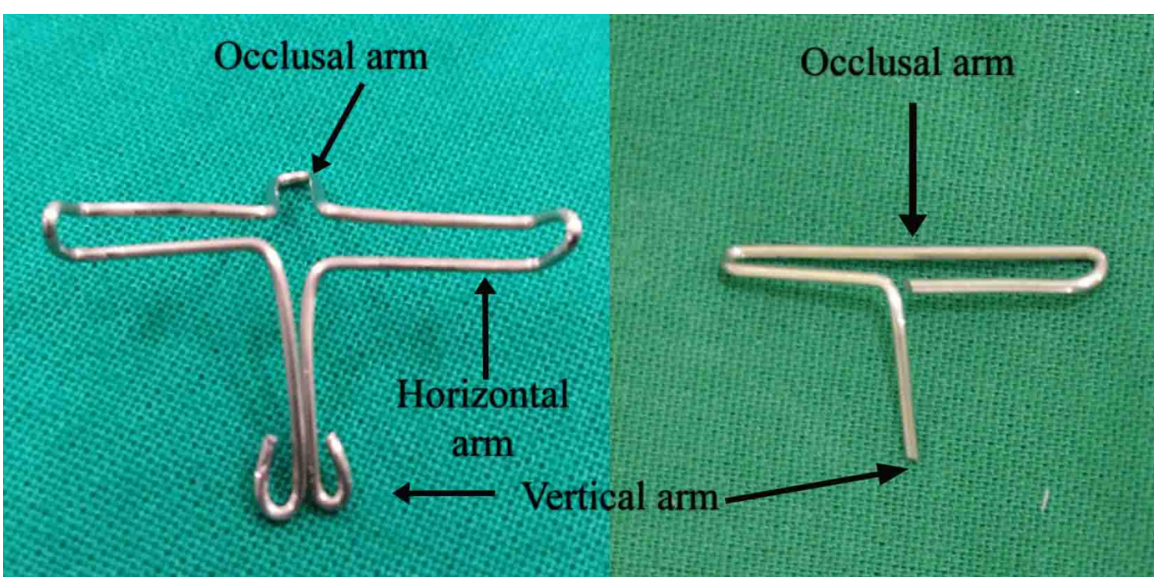

Figure 3: Fabricated Buccal and Lingual wire components

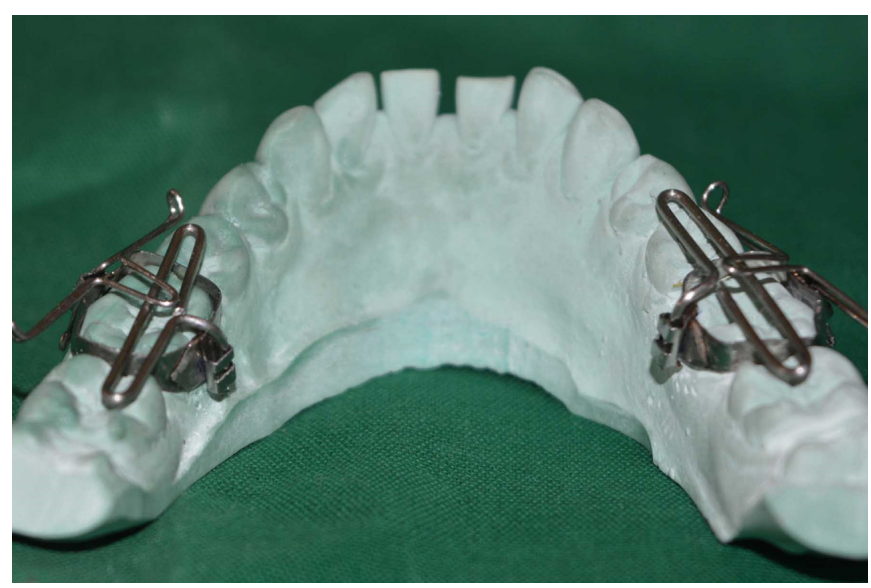

Figure 4: Molar Bands with Vertically Oriented Lingual sheath along with wire parts

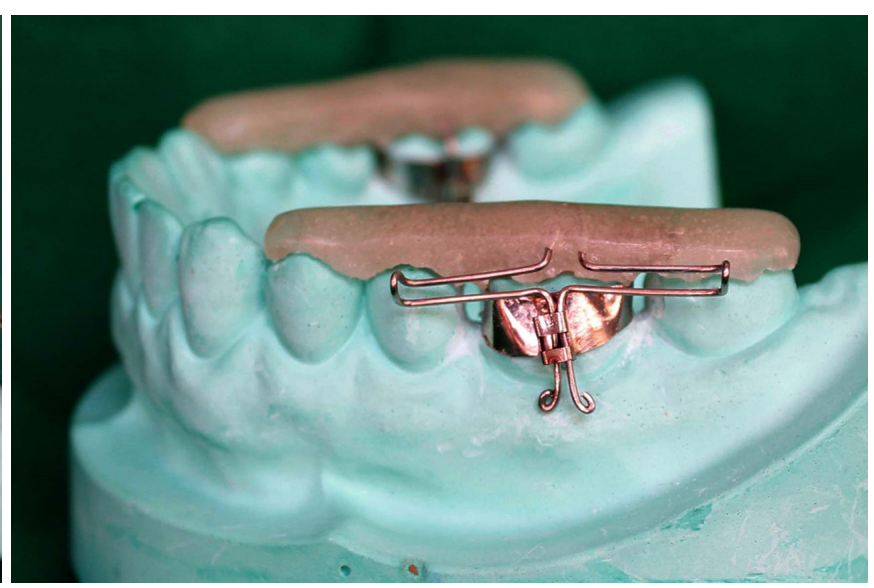

Figure 5: Acrylized appliance Fitted on the Cast

OJN

\section{REFERENCES}

1. Ceen RF. Bite opening with the Güray Bite Raiser. J Clin Orthod. 2002 Nov;36(1 1):639-40

2. Vibhute PJ, Srivastava S, Hazarey PV. Temporary bite-raising crowns. J Clin Orthod. 2006 Apr;40(4):224-30 